\title{
Automatic Parallel Car Parking System using Sensors and Arduino UNO
}

\author{
Soma Ram Ganesh, V.Sai Ganesh, Mir Farazuddin Hamza, Sahil Ramwal , Siddhartha Ghosh
}

\begin{abstract}
In this busy world, people are tending towards automation in all routine works which in turn is saving their time. Due to the increased use of cars and congesting places, everywhere we are facing a queue to pass through. One such queue we face is in the parallel parking lots. For solving this problem, many automobile manufacturers have come up with Auto Parking Features in New Model Cars. Then what about Old Cars? Shouldn't those Old Cars get modified with this Auto Parking facility? Yes, they can get modified with our proposed solution. In this paper, we are presenting a solution in the form of a module for the parallel parking problem called "Automatic Parallel Car Parking System - using Sensors and Arduino UNO". Along with New Cars, this module can also be integrated with Old Electric Cars to bring Auto Parallel Park feature. This paper also discusses existing Auto Parallel Parking Systems. It also discusses the proposed solution by solving the flaws in existing solutions. The proposed solution is easily adaptable, with small modifications to an electric car. Future enhancements are also proposed.
\end{abstract}

Keywords: Auto Parallel Parking, ultrasonic Sensors, IR Sensors, Arduino UNO, Autonomous Parking, Self Parking

\section{INTRODUCTION}

In recent years, Microcontrollers, Electronic Components, Sensors, Actuators, etc have become so advanced and cost efficient that, many real world problems are easily being solved using them in low cost with high accuracy. Based on the program written and dumped by the programmer, the processor (or) controller used sensors data and makes the actuators work accordingly. We have chosen Arduino UNO Open Source Microcontroller and Arduino IDE over its other competitors because of its efficiency, easy to use and availability of vast libraries. Embedded $C$ language is used in Arduino IDE to program this microcontroller. In this, we are proposing a module with a circuit which helps the Car parallel park autonomously.

\section{RELATED WORK}

As we are aware that, the problem in finding a car parking slot(mentioned in [5] and [9]) is very high in populated cities and we have to park our vehicle in these congested slots which

Revised Version Manuscript Received on 16 September, 2019.

* Correspondence Author

Soma Ram Ganesh, is a student pursuing Bachelors in Electronics and Communication Engineering in Vidya Jyothi Institute of Technology, Hyderabad Email: somaganesh47@gmail.com

V.Sai Ganesh, is a student pursuing Bachelors in Electrical and Electronics Engineering in Vidya Jyothi Institute of Technology, Hyderabad, India.. Email: saiganesh223468@gmail.com

Mir Farazuddin Hamza is student pursuing Bachelors in Electrical and Electronics Engineering in Vidya Jyothi Institute of Technology, Hyderabad, India. Email: faraazhamza@gmail.com

Sahil Ramwal is a student pursuing Bachelors in Computer Science and Engineering in Vidya Jyothi Institute of Technology, Hyderabad, India. Email sahilramwa199@gmail.com

Dr. Siddhartha Ghosh is a Professor in CSE Dept at Vidya Jyothi Institute of Technology. Email: siddhartha@ vjit.ac.in is a big issue. So this realization made us work on automatic parallel parking system because a computer can park more efficiently(requires a slot only with the more (or) exact dimensions as of car) than a human(requires higher slot dimensions than car dimensions for the driver getting out of the car after parking, etc).

In our research, we have come across the works on Auto Parallel parking through various approaches and technologies like Image Processing in [8], using Simulink \& Matlab in [7], using Microcontroller \& Ultrasonic sensors in [6] [3].

Since Image Processing may require heavy performance processors, we haven't chose Image Processing Techniques as a choice of working instead thought of using sensors like IR sensors and Ultrasonic sensors.

We used IR and Ultrasonic sensors because, as of [1] IR works fine for obstacles made of Paper sheets, cardboard, Rubber, etc and Ultrasonic works fine for obstacles made of Sponge, Wood, Plastic, Tile, Rubber, Cardboard, etc.So a combination of both covers a wide range of Obstacle materials.

Since Matlab \& Simulink are Commercial Softwares, the R\&D of the final product may go high, so we decided to choose Open Source Tools.

While searching for Open Source Tools, we came across Arduino Boards (is Open source and Effective than its Competitors) through [2].

Then in the proposed solution, for using Arduino with Sensors we have referred some other inspiring and encouraging works in [6], [3], [5], [4] and came up with a solution in out point of view.

One of the modifications which we had made is making a Module to get integrated with an electric car motor to enable Auto Park Facility.

\section{AUTOMATIC PARALLEL PARKING SYSTEM (PROPOSED SYSTEM)}

\section{A. Components Used:}

1). Arduino UNO: It is a Microcontroller development board which has many electronic components embedded onto it which reduces our burden of connecting those small components manually by us. This Microcontroller can be easily programmed in an Open Source Arduino IDE using Embedded $\mathrm{C}$ language. The reason behind choosing this Microcontroller is the presence of huge number of pre made Open Source libraries. We use one Arduino UNO in the proposed solution.

2). IR Sensor: It is an electronic device which emits radiation to sense the aspects of the surroundings. It has

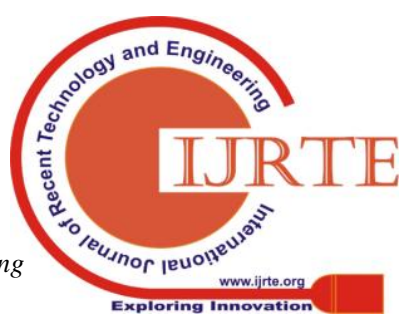


built in Infrared Receiver and Transmitter. The IR Transmitter emits Infrared radiation and the IR Receiver receives the transmitted radiation. Using this technique, this device does Obstacle Detection. When the Obstacle is detected, the OUT pin of the device gets a High Voltage signal which helps the Controller to know that the Obstacle is present in front of the device. We use 4 of them(left, right, front, back) in the proposed solution.

3). Ultrasonic Sensor: It is an electronic sensor which emits and receives ultrasonic waves to measure the distance from an obstacle. It emits an Ultrasonic wave of $40,000 \mathrm{~Hz}$ which travels at the speed of sound. The transmitted signal will collide with the Object present at a certain distance and then gets reflected back. The reflected Ultrasonic signal with then be sensed by the Receiver of the Ultrasonic Sensor which helps in calculating the time between transmission and reception. So, now these Speed and Time values are used to calculate the Distance between the Sensor and the Object. We use 2 of them in the proposed solution.

4). L293D Motor Driver: This is an electronic component designed with Dual H-Bridge circuit which helps in controlling two DC Motors independently(i.e. in either directions). H-Bridge is a circuit which allows the flow of electrons in either direction. As we know that, voltage needs to change direction to in order to change the direction of the wheel rotation. Here H-Bridge can be used in changing the direction of the DC Motors. In electric cars, we can use this component to connect to the main DC Motors.

5) . Jumper Wires: These are the normal connecting wires with connector pins on both sides which help in easy connecting of electronic components. Both the ends of the wire have pins which help in easy connection of any two electronic components.

In Figure 1, the schematic diagram represents the entire circuitry of the proposed system. All the components have been connected to the Arduino UNO through the Digital I/O pins of the Arduino UNO Board.

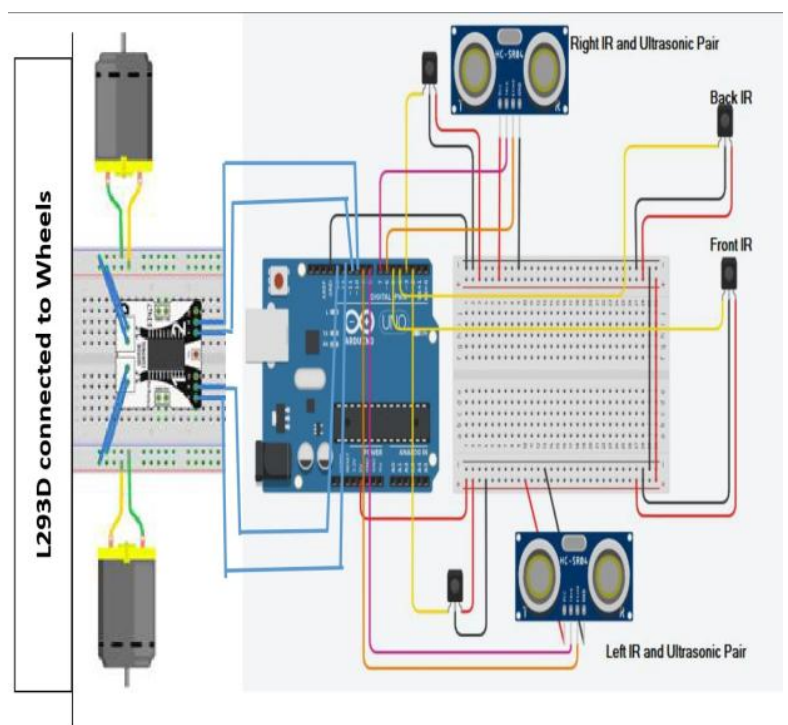

Figure 1: Schematic Diagram of the Prototype

In Figure 2, we have explained the Complete Work Flow of the proposed solution using a Flow Chart

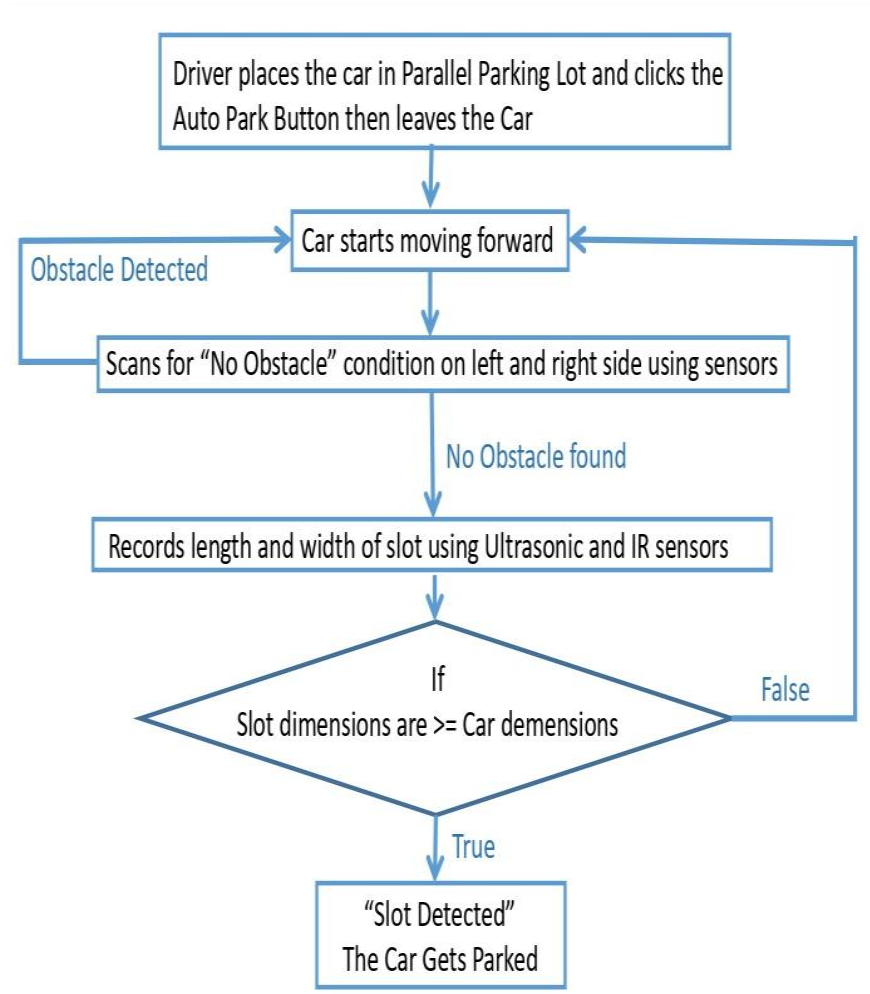

Figure 2: Work Flow of the proposed solution

B. Working: The car autonomously parks itself in a parallel parking slot when pressed a button and left alone. The car will have an IR sensor on left and right side (each facing left and right directions) near to the front wheels, and Ultrasonic sensors on left and right side(each facing left and right directions) near to the rear wheels. The distance between the IR and Ultrasonic sensor is adjusted as the size of car's width. The conditions to be satisfied are the Slot Dimensions $>=$ Car Dimensions (i.e. Slot's width and length \& Car's width and length). Let us now consider a scenario of a parking lot with parking slots on left side. Now the driver can move out of the car and the car automatically parks itself in an empty parking slot on left side. Let us consider the driver has moved out of the car, now autonomously the car starts moving forward and simultaneously checks for any obstacle in front of left IR sensor. When the IR sensor detects no obstacle then the car continues moving forward and simultaneously the left Ultrasonic sensor starts reading the distance from the left side obstacle. If the IR and Ultrasonic sensor detect no obstacle simultaneously, it means that the slot's width is $>=$ car's width(a). Simultaneously the Ultrasonic sensor checks for the depth of the parking slot, if the depth of the parking slot is >= car's length(b) then the car stops moving forward.

If the conditions (a) and (b) are satisfied, the right wheels move backward till the car makes a 90 degree angle(the 90 degree angle is measured by rotating the wheel until 90 degree angle is obtained by manipulating the circumference of the wheel). Then the car moves backward into parking slot and the IR sensor at car's back help in avoiding collision. Hence the car is reverse parked. For electric cars, we integrate this setup to the main Motors of the Car with the help of L293D Motor Driver. 


\section{EXPERIMENTAL RESULTS}

In Figure 3, we have shown the Top View Graphic Diagram of the Work Flow. We have divided the diagram into I and II. In $\mathbf{I}$, the Blue Car in the diagram is searching for an Empty Slot on its Left Side using the Sensors and simultaneously moving forward.

In II, the Blue Car has detected an Empty Slot and it is Parking itself.
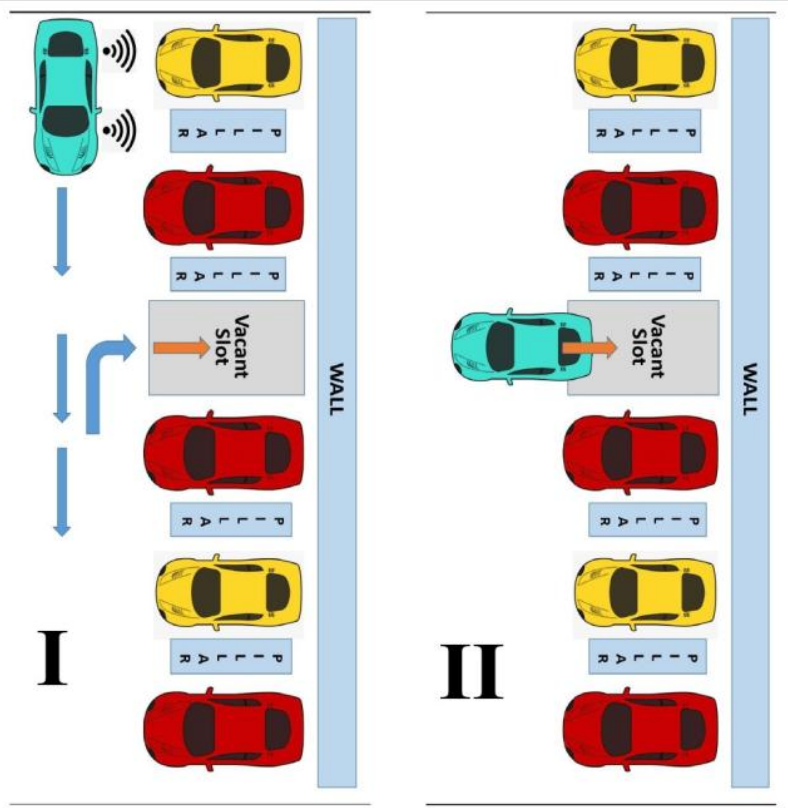

Figure 3: Simulated View

In Figure 4, we have shown the working model made using the mentioned Components and a Basic Chassis with a pair of Wheels.

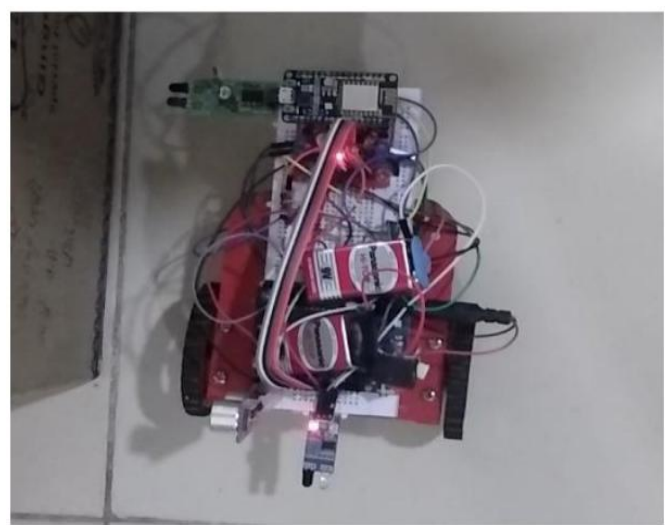

Figure 4: Left Side Park enabled model

Figure 5, 6, 7, 8 represent the procedure of parking from staring to ending.

In Figure 5, the Car has started moving forward and it is detecting for an Empty Slot on its Left Side. We have used cardboard pieces as the walls (or) parked cars (or) obstacles.

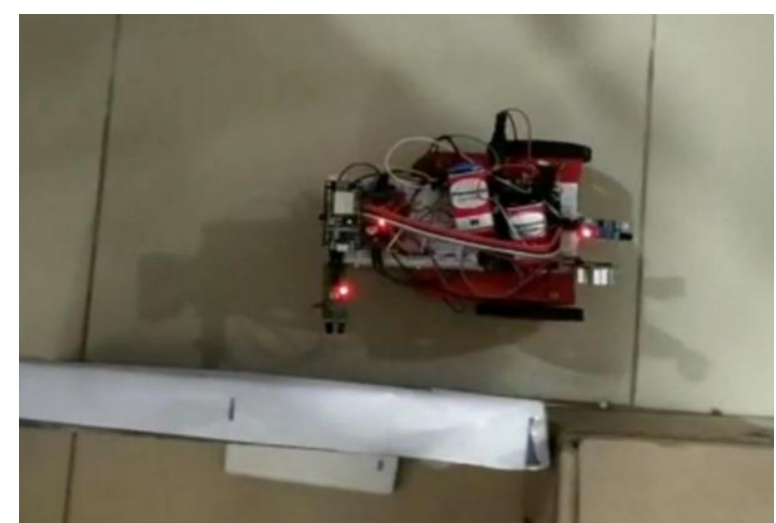

Figure 5: Car searching for Slot on its Left Side

In Figure 6, the car has detected an empty parking slot and has stopped moving further.

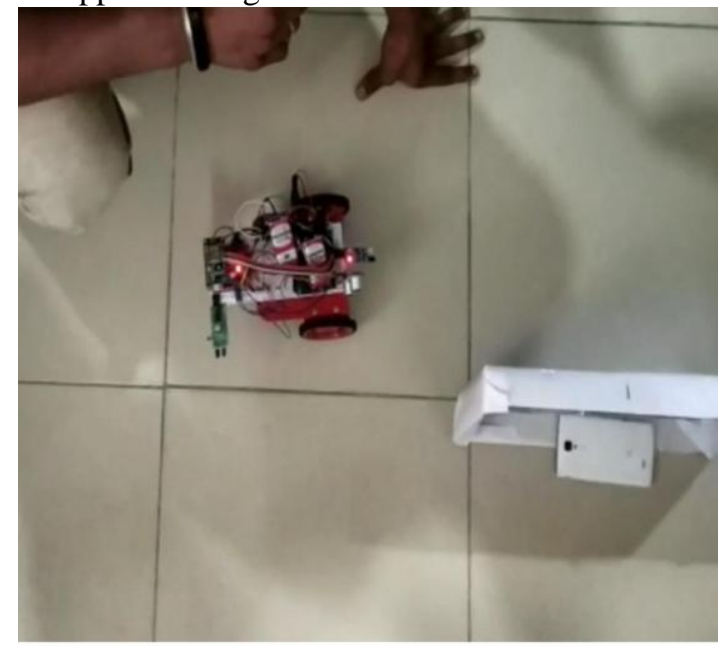

Figure 6: Car Detected a slot on its Left Side

In Figure 7, the Car is turning towards the Parking Slot and then it starts moving backwards.

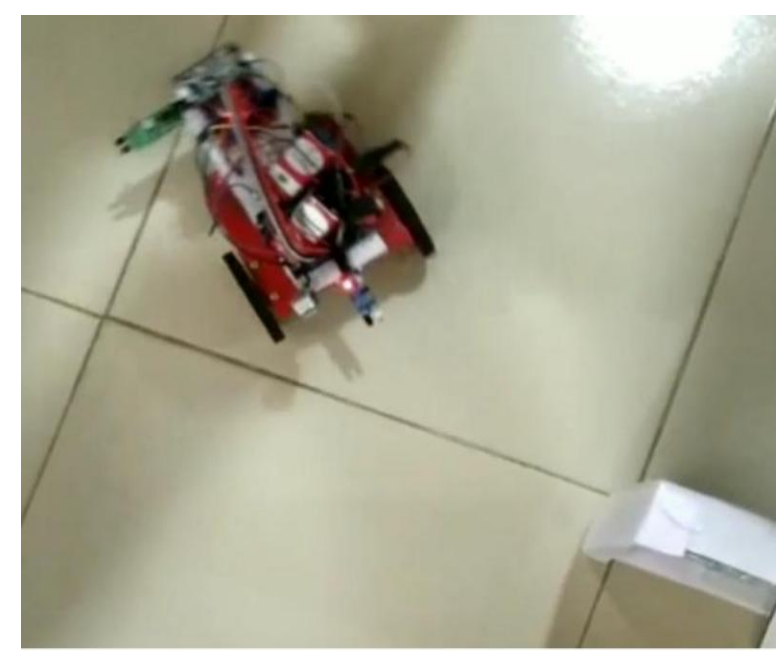

Figure 7: Car turning towards the Detected Slot

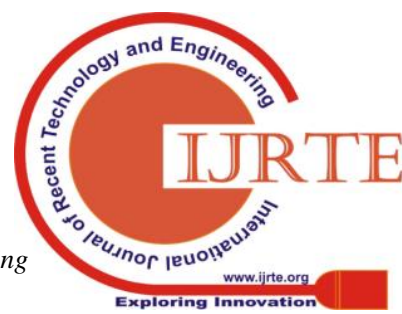


In Figure 7, the Car has moved backward into the Parking Slot. The Car moves backward untill the back IR sensor detects for an Obstacle.

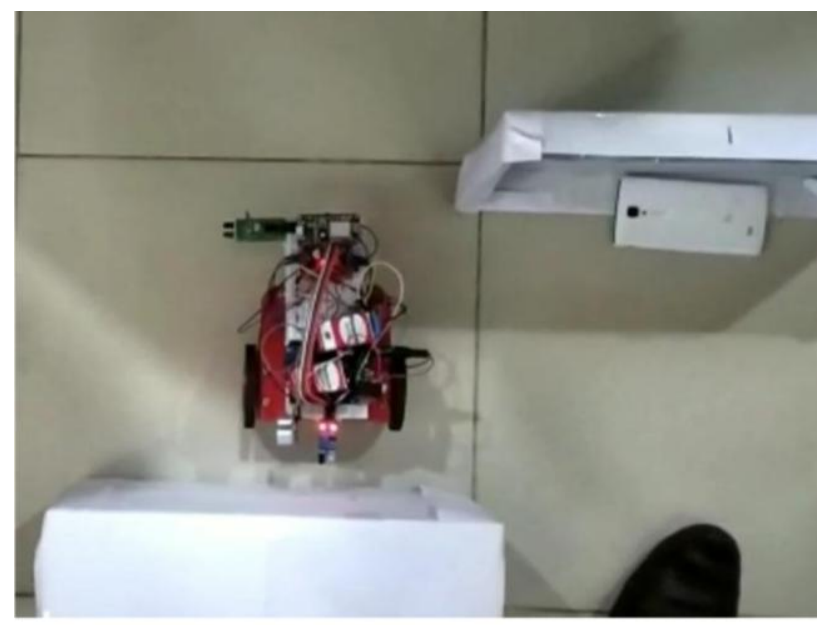

Figure 8: Car Parked Successfully

Finally the Car has Parked itself in a Parallel Parking Slot.

Entire work is availabe on our github repository ( https://www.github.com/Ramganeshsoma/automatic-parallel -car-parking ).

\section{FURTHER ENHANCEMENTS}

A. Making a module which can be integrated even with Old Petrol Engine Cars to enable Self Parking Facility.

B. After self parked, the car will send a confirmation SMS to the Driver's mobile using a GPD module.

C. Making it much more accurate in parking the car and cost efficient using only Open Source tools.

D. Making a Visual 3D model of the moving car(using sensor coordinates of 3-axis accelerometer) while self parking and cast the Visuals on the Driver's Mobile App.

\section{CONCLUSION}

The Auto parking is necessary for all of us, as it saves a lot of time. The current solutions in market are not cost efficient and the auto park functionality is present only in luxury cars. But the proposed solution can provide the auto parking functionality to a normal and old car also. We are trying to integrate this Auto Park Module with the controllers of the normal electrical car to add the auto park functionality to it.

\section{REFERENCES}

[1] Adarsh S1, Mohamed Kaleemuddin S1, Dinesh Bose1, K I Ramachandran2 S Adarsh et al 2016 IOP Conf. Ser.: Mater. Sci. Eng. 149 012141, Performance comparison of Infrared and Ultrasonic sensors for obstacles of different materials in vehicle/ robot navigation applications, ICon AMMA 2016, Pp - 7

[2] Avinash Kumar Shudhanshu, Raj Kumar, Sadashiv Raj Bharadwaj, Gaurav Singh, Amit Garg, Technology based laboratory to improve science learning

[3] Claire Chen, The Menlo Roundtable, Autonomous Parallel Parking Car, 2015
[4] Dhiraj Thote, Harsha Tembhekar, Ankit Bharambe, Ankit Bansod, Mayur Meshram, Prajit Meshram, Automatic Self-Parking Chair, International Research Journal of Engineering and Technology (IRJET) Volume: 05 Issue: 03 Mar-2018

[5] Maksura Mubashirin, Srabosti Mahmud, Automated Car Parking System

[6] Ray_Shine Run 1, Jui-Cheng Yen 2, and Chihhsuan Chen, A Study of Automatic Parallel Parking System - from the Viewpoints of User and Manufacturer, July - 2011

[7] Roberto Cabrera-Cósetl, Miguel Zeus Mora-Álvarez, Rubén Alejos-Palomares, Self-Parking System Based in a Fuzzy Logic Approach, 2009 International Conference on Electrical, Communications, and Computers

[8] Shidian Ma, Haobin Jiang, Mu Ha, Ju Xie, Chenxu Li, Research on Automatic Parking Systems Based on Parking Scene Recognition, Published October 18, 2017

[9] Suvarna Nandyal, Ph.D., Sabiya Sultana, Sadaf Anjum, Smart Car Parking System using Arduino UNO, International Journal of Computer Applications (0975 - 8887)Volume169 - No.1, July 2017

[10] Tom Airaksinen, Hedvig Aminoff, Erik Byström, Gustav Eimar, Iracema Mata, David Schmidt Cognitive Science Program, University of Linköping, June 2004, Automatic Parallel Parking Assistance System User Interface Design - Easier Said Than Done?

\section{AUTHORS PROFILE}

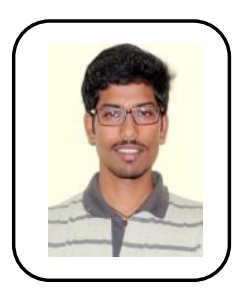

Soma Ram Ganesh is a student pursuing Bachelors in Electronics and Communication Engineering in Vidya Jyothi Institute of Technology, Hyderabad, India. His interests are in Internet of Things Applications, Electronics, Machine Learning, Data Science.

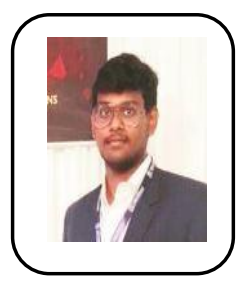

V. Sai Ganesh is a student pursuing Bachelors in Electrical and Electronics Engineering in Vidya Jyothi Institute of Technology, Hyderabad, India. His interests are in Internet of Things Applications, Machine Learning, Data Science.

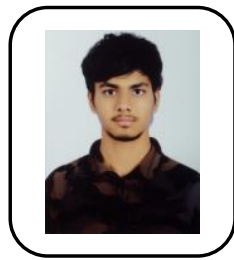

Mir Farazuddin Hamza is student pursuing Bachelors in Electrical and Electronics Engineering in Vidya Jyothi Institute of Technology, Hyderabad, India. His interests are in Internet of Things Applications, Data Science.

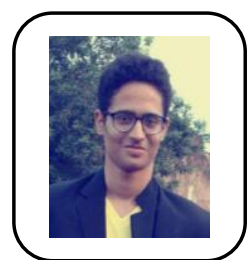

Sahil Ramwal is a student pursuing Bachelors in Computer Science and Engineering in Vidya Jyothi Institute of Technology, Hyderabad, India. His interests are in Internet of Things Applications, Data Science.

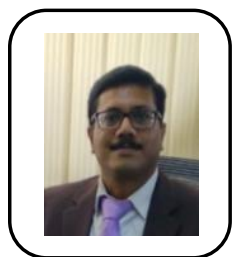

Dr. Siddhartha Ghosh is a Professor in CSE Dept at Vidya Jyothi Institute of Technology with 18 years of teaching and research experience. His areas of interests are AI, ML, IoT, Big Data, NLP etc. 